\title{
Slip, trip and falls among women of different age groups: A case study from the northern hills of India
}

\author{
Hema Bhatt*, Promila Sharma \\ 263153 (Uttarakhand), INDIA \\ *Corresponding author. E-mail: hemabhatt2000@fulbrightmail.org \\ Received: July 20, 2016; Revised received: January 23, 2017; Accepted: February 25, 2017
}

Department of Family Resource Management, G. B. Pant University of Agriculture \& Technology, Pantnagar-

\begin{abstract}
Slip, trip and falls continue to be significant occupational safety concern, and causes of occupational injuries and fatalities in the workplace and daily activities. This paper shows the results of a comparative study done in the hill region of India. It explored the slip, trip and fall injuries in terms of activities leading to them and impact of such injuries among the hill women of different age groups: young adults, middle aged and elderly. It was found that most of the slip, trip and falls were faced during the activity of carrying fodder $(52.78 \%)$, carrying firewood (49.44 $\%$ ), collecting fodder (47.78 \%), collecting firewood (43.89\%) and collecting dung (40.56\%). Most of the slip accidents were reported by elderly age group as compared to middle aged and young adults. Majority of the respondents got hurt their back and/or they suffered from back pain $(76.67 \%)$, faced general pain $(72.22 \%)$ and fractures $(45.00 \%)$. Most of the respondents reported the possible perceived reason for slip, trip and falls as slippery terrain $(82.78 \%)$, followed by $80.00 \%$ of respondents who reported carrying excess load as the major reason. Other reasons reported were being rushed at work (77.77\%), awkward or unusual working posture (76.66 \%). This study brings in light the dangerous working conditions of hill women, who often suffers from many injuries including slip, trip and falls even just for meeting her daily family needs such as water, fuel, fodder.
\end{abstract}

Keywords: Accidents, Falls, Hills, Slip, Trip

\section{INTRODUCTION}

Slip, trip and falls (STF) persist as a significant burden to society both in terms of human suffering and economic losses. Numerous epidemiological studies related to STF have been reported in the literature (Manning et al.,1981; Berg et al., 1997; Davis et al.,1999; Kemmlert and Lundholm, 2001; Rubenstein, 2006) and the scale of the problem has been recognised over several decades (Strandberg and Lanshammar, 1981; Buck and Colman 1985; Leamon and Murphy, 1995; Kemmlert and Lundholm, 1998; European Agency for Safety and Health at Work (EU-OSHA) 2001; European Commission, 2008; Nenonen, 2013; Yeoh et al., 2013).

STF are common incidents and can be caused anywhere either in an internal environment like office setting, a school, a public building, a warehouse or in an outside environment like on roads or agricultural fields. Slips and falls are one of the most frequent causes of occupational accidents (Lincoln, 2004; BLS, 2012) and are associated with high rates of injury, disability, and death at the workplace (BLS, 2012).

Slip and falls are one of the major problems in the elderly age group and are considered one of the "Geriatric Giants". The frequency of falls increases with age and frailty level (WHO, 2008). More than a third of people aged 65 and older living independently fall each year (Tromp et al., 2001) and falls are the leading cause of injury-related deaths and hospital emergency department visits (CDC, 2013). In India, population of older adults is rising. The projected number for people aged 60 years and above in 2021 is 137 million (Registrar General of India and Centre for Global Health Research, 2009). Small regional studies in India have reported higher rates of deaths from falls than have been reported earlier, even among older age groups (Gururaj et al., 2008; Dandona et al., 2010; Krishnaswamy and Usha, 2010). As per a study done by Jagnoor et al. (2011), falls on the same level, such as slipping and tripping, caused most of the deaths. It was also highlighted in their study that women aged 70 years or over had higher rates of death from falls than men.

A vast majority of researches related to slip and falls have concentrated on the prevention of indoor accidents (Donoghue, 2003; Hitcho et al., 2004; Nakai et al., 2006; Nachreiner et al., 2007) where the surfaces can be relatively uniform and the environment can be controlled. But there is paucity of researches as only a few studies (Gronqvist and Hirvonen, 1995; Abeysekera, 2001; Gao and Abeysekera, 2004) have fo- 


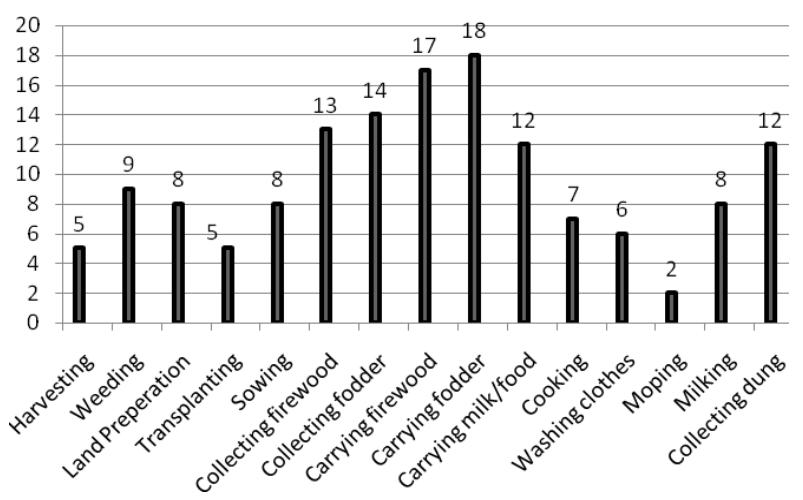

Fig. 1. Number of STF injury cases during performance of various activities among young adults.

cused on the outdoor environment which, particularly in an external environment like at hills, is far less controllable and predictable. Environment and exposures at hills such as an inclined or sloped ground surface, slippery terrain etc. pose an individual to at an increased risk of instability, and ultimately falls. An inclined surface has been frequently considered as an obstacle, and such surfaces can cause an increased chance of falling due to slippage or loss of balance (Redfern and DiPasquale, 1997; Leroux et al., 2002). Working at such slopes often result in STF accidents not only while working outdoors but they are even faced during normal walking by the pedestrians and the general public. STF prevention is a challenge to the older population in such interior rural area. With the anticipated progressive increase in the number and fraction of elderly people, falls are bound to increase dramatically in coming years and will impose a commensurate burden on families and health-care systems. So this study was undertaken with the objectives:i) To investigate among different age groups the activities leading to STF, ii)To identify the immediate effect of the STF in different age groups, iii) To explore among different age groups the possible perceived reasons of STF.

\section{MATERIALS AND METHODS}

Study settings: This study was done in the hill regions of Uttarakhand state in India. Most of the hill area of

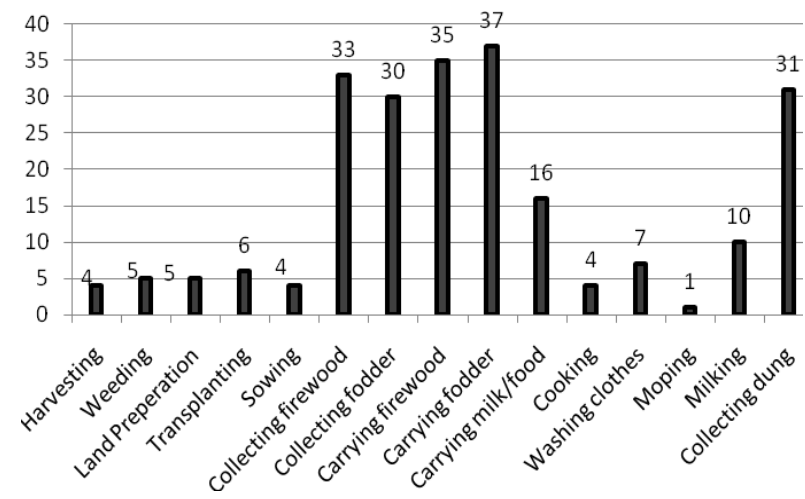

Fig. 2. Number of STF injury cases during performance of various activities among middle aged.

this state are remote and are less developed in terms of infrastructure, i.e., electricity, roads and irrigation (Mittal et al., 2008).Terrain and degraded environment makes daily routine of collecting fodder, fuel and water, a time consuming, daunting and fatal task. Often slips occur during walking uphill or downhill while carrying the heavy loads of fodder and water due to forces generated at the feet and poor frictional properties of the footwear/ sloping surface. The heavy work and adverse working conditions of people especially women in hills is gruelling taking a heavy toll of them and one of the possible major reason being the STF.

Two districts of the state i.e. Almora and Bageshwar were purposively selected for the study. One block from each district i.e. Kapkot and Hawalbagh were selected to make a total sample of 180 . Only females were purposively selected as worldwide, in populationbased studies, the incidence of falls is reported to be higher amongst females and most of these falls are amongst women aged 60 years and older, including in India (Sattin et al., 1990; Tinetti, 2003; Johnson, 2006; Navaratne et al., 2009; Jagnoor et al., 2011). Equal number of samples was purposely selected from three age groups i.e. 60 young adults, 60 middle aged and 60 elderly. Simple random sampling technique without replacement was used for study. The pre-coded interview schedule was found to be an appropriate tool, which would gather the required information pertaining to research work. Information regarding demo-

Table 1. Socio-economic profile of the respondents.

\begin{tabular}{lcccc}
\hline & & Age groups & Total Respondents \\
Variables & Young Adults $(\mathbf{n}=\mathbf{6 0})$ & Middle Aged $(\mathbf{n}=\mathbf{6 0})$ & Elderly $(\mathbf{n}=\mathbf{6 0})$ & \\
\hline Occupation & & & & $04(02.22)$ \\
\hline Homemaker & - & - & $04(6.67)$ & $165(91.67)$ \\
Self farming & $54(90.00)$ & $55(91.67)$ & $56(93.33)$ & $05(02.78)$ \\
Tenant farming & - & $05(08.33)$ & - & $06(03.33)$ \\
Private job & $06(10.00)$ & - & - & $57(31.67)$ \\
\hline Monthly family income (Rs) & $10(16.66)$ & $19(31.66)$ & $28(46.66)$ & $117(65.00)$ \\
\hline Below 5000 & $45(75.00)$ & $40(66.67)$ & $32(53.33)$ & $06(03.33)$ \\
5000-10000 & $05(08.33)$ & $01(01.67)$ & - & \\
More than 10000 & & & & \\
\hline
\end{tabular}

Figure in parentheses indicate the percentage values 
Table 2. STF injury cases reported by respondents while performing different activities.

\begin{tabular}{lc}
\hline Activity & Number of STF injury cases \\
\hline On Farm Activities & \\
\hline Harvesting & 17 \\
Weeding & 20 \\
Land preparation & 19 \\
Transplanting & 26 \\
Sowing & 16 \\
\hline Off Farm Activities & \\
\hline Collecting Firewood & 79 \\
Collecting Fodder & 86 \\
Carrying Firewood & 89 \\
Carrying Fodder & 95 \\
Carrying Milk/Food & 46 \\
\hline Domestic Activities & \\
\hline Cooking & 16 \\
Washing Clothes & 18 \\
Mopping & 6 \\
Milking & 28 \\
Collecting Dung & 73 \\
Total & 634 \\
\hline
\end{tabular}

graphic details of respondents and in-depth information regarding STF injuries in various work activities, its immediate effect and their individual experiences of STF faced during the last six months were recorded. In addition, focus group discussions were organized to know perceived reason that they considered responsible for STF injury. The data collected were tabulated and suitable statistical tool such as frequency, averages and percentages were used for analysis of data.

\section{RESULTS AND DISCUSSION}

Socio-economic profile of the respondents: Socioeconomic profile of the respondents was analysed in terms of occupation and monthly income and is presented in Table 1. It was found that of the total respondents, majority i.e. $91.67 \%$ were engaged in self farming, followed by $03.33 \%$ who were employed in private job. Also $02.22 \%$ of respondents were homemakers and almost equal $(02.78 \%)$ respondents were engaged in tenant farming. Among different age groups also it was observed that majority in each cate-

Table 3. Possible perceived reasons of STF proposed by the respondents of different age groups.

\begin{tabular}{|c|c|c|c|c|}
\hline Perceived Reason for STF & & $\begin{array}{c}\text { Young } \\
\text { Adult }(\mathrm{n}=60)\end{array}$ & $\begin{array}{c}\text { Middle Age } \\
(\mathbf{n}=60)\end{array}$ & $\begin{array}{c}\text { Elderly } \\
(\mathbf{n}=60)\end{array}$ \\
\hline \multirow[t]{4}{*}{ Biological } & Older age & - & - & $33(55.00)$ \\
\hline & Sex (being female) & - & - & $3(05.00)$ \\
\hline & Overweight & - & $6(10.00)$ & - \\
\hline & Underweight & - & $26(43.33)$ & $38(63.33)$ \\
\hline \multirow[t]{7}{*}{ Medical condition/individual factor } & Osteoporosis & - & $16(26.66)$ & $35(58.33)$ \\
\hline & Anxiety & - & - & $9(15.00)$ \\
\hline & Poor gait balance & $12(20.00)$ & $22(36.66)$ & $40(66.66)$ \\
\hline & Muscle weakness & - & $21(35.00)$ & $27(45.00)$ \\
\hline & Visual Impairment & - & - & $32(53.33)$ \\
\hline & Foot problem/ Leg problem & $5(08.33)$ & $21(35.00)$ & $39(65.00)$ \\
\hline & Fatigue & $13(21.66)$ & $15(25.00)$ & $38(63.33)$ \\
\hline \multirow[t]{9}{*}{ Environmental } & Poor visibility & $34(56.67)$ & $46(76.67)$ & $54(90.00)$ \\
\hline & Uneven land & $38(63.33)$ & $24(40.00)$ & $37(61.67)$ \\
\hline & Precipitation & $38(63.33)$ & $43(71.67))$ & $24(40.00)$ \\
\hline & Slippery terrain & $48(80.00)$ & $48(80.00)$ & $53(88.33)$ \\
\hline & Obscured view of underfoot hazard & $8(13.33)$ & $6(10.00)$ & $10(16.66)$ \\
\hline & $\begin{array}{l}\text { Unable to assess hazard/ Hazard seen but } \\
\text { not assessed as STF hazard }\end{array}$ & $31(51.67)$ & $34(56.67)$ & $43(71.67)$ \\
\hline & Rain & $18(30.00)$ & $12(20.00)$ & $21(35.00)$ \\
\hline & Floor/ stairs & $11(18.33)$ & $9(15)$ & $17(28.33)$ \\
\hline & Pine needles & $36(60.00)$ & $42(70.00)$ & $30(50.00)$ \\
\hline \multirow{4}{*}{ Work equipment /accessories } & Inappropriate performing equipment/tool & $25(41.66)$ & $14(23.33)$ & $12(20.00)$ \\
\hline & Lack of safety equipment & $34(56.66)$ & $31(51.66)$ & $42(70.00)$ \\
\hline & Poor fitting Footwear & $31(51.66)$ & $24(40.00)$ & $21(35.00)$ \\
\hline & Unusual tool/equipment & $44(73.33)$ & $48(80.00)$ & $41(68.33)$ \\
\hline \multirow[t]{4}{*}{ Workplace /Work task related } & Unusual/altered work method & $47(78.33)$ & $45(75.00)$ & $43(71.67)$ \\
\hline & Unusual task & $5(08.33)$ & $16(26.66)$ & $12(20.00)$ \\
\hline & New workplace/ environment & $46(76.66)$ & $38(63.33)$ & $31(51.66)$ \\
\hline & Working more than usual hours & $27(45.00)$ & $37(61.66)$ & $16(26.66)$ \\
\hline \multirow[t]{4}{*}{ Work related factors } & Distracted & $46(76.66)$ & $38(63.33)$ & $28(46.67)$ \\
\hline & Being Rushed & $45(75.00)$ & $46(76.66)$ & $49(81.66)$ \\
\hline & Awkward/unusual working posture & $43(71.66)$ & $48(80.00)$ & $47(78.33)$ \\
\hline & Carrying excess load & $48(80.00)$ & $49(81.66)$ & $47(78.33)$ \\
\hline
\end{tabular}



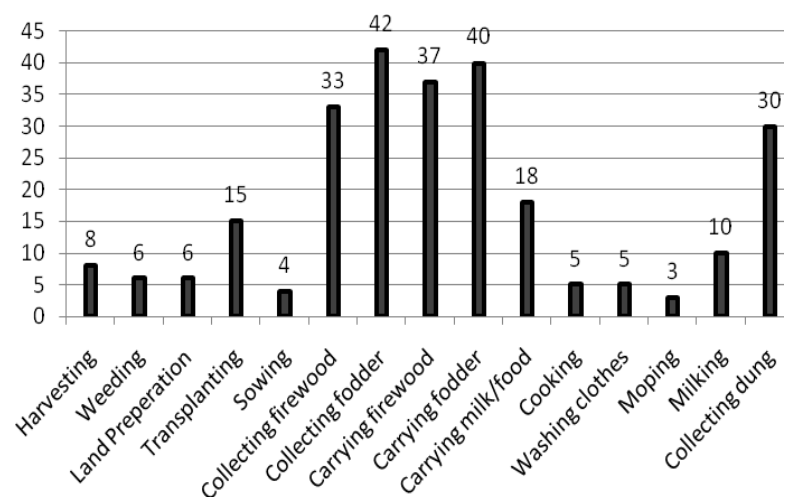

Fig. 3. Number of STF injury cases during performance of various activities among elderly.

gory i.e. $90.00 \%$ young adults, $91.67 \%$ of middle aged and $93.33 \%$ of elderly were engaged in self farming as their occupation. The reason for majority of the respondents engaged in self farming was that they had no other means of occupations like to start their own business and most of them were illiterate so they neither could opt for other occupation nor could apply for government jobs, hence, either working on their own farms or on the farms of others as labourers were the only options for most of them.

Monthly Income of the respondents indicated that of the total respondents more than half i.e. $65 \%$ were having monthly family income in between Rs 5000 to 10000 . It can further be seen from table 1 that in majority of the age groups i.e. $75.00 \%$ of young adults, $66.67 \%$ of middle aged and $53.33 \%$ of elderly monthly family income was in between Rs 5000 to 10000 .

Identification of STF at work among different age groups: Data pertaining to STF at work in different age group respondents was gathered. It was found that in total 634 cases of STF injuries were reported by 180 respondents (Table 2) in the last six months. The various activities where STF injuries were reported included the on farm activity of harvesting, weeding, land preparation, transplanting, sowing. The off farm activities included collecting firewood, collecting fodder, carrying firewood, carrying fodder and carrying milk/ food. The domestic activities where STF cases were reported included cooking, washing clothes, milking, mopping and collecting dung.

The reported cases of STF were analyzed and it was found that on the whole most of the STF injuries (95 cases) were reported during carrying fodder activity, followed by 89 cases of STF reported during carrying firewood. 86 cases of STF injuries were reported during collecting fodder and during collecting firewood 79 cases were reported (Table 2). Many respondents also reported collecting dung as the activity during which they faced STF i.e. 73 cases. Other noticeable STF prone activities reported were carrying milk/food (46 cases), milking (28 cases), transplanting (26 cases)

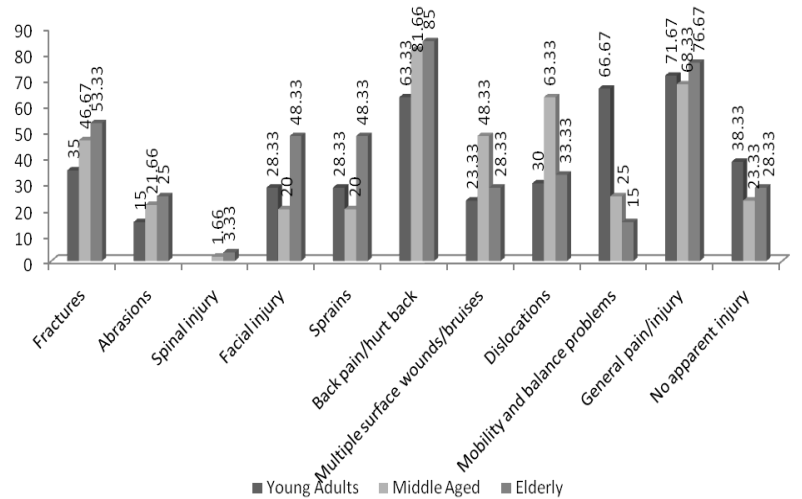

Fig. 4. Immediate effect of STF among different age group respondents (percentage).

and weeding (20 cases). During land preparation (19 cases), washing clothes (18 cases), harvesting (17 cases) and cooking (16 cases) also STF were reported.

Further, it was found that in young adults age category major STF prone activity was found to be carrying fodder where 18 cases were reported, followed by carrying firewood where 17 cases were reported and collecting fodder (14 cases) (Fig. 1). Among middle aged major STF prone activity was found to be carrying fodder where 37 cases were reported, followed by 35 cases reported during carrying firewood, and 33 cases of STF injuries during collecting firewood (Fig. 2). Whereas among elderly most STF prone activity reported was collecting fodder where 42 cases were reported, followed by carrying fodder (40 cases), and 37 cases of STF in carrying firewood (Fig 3).Fall from height was also reported by Kumar and Singh (2013) as second most common cause of injury in hill areas after road accidents.

It can also be analysed that more STF accidents were reported by elderly age group compared to middle aged and young adults. Of the total 634 cases of STF injury young adult age category respondents reported 144 cases, middle aged reported 228 cases and elderly respondents reported 262 cases of STF injuries. Earlier studies (Sattin et al. 1990; WHO, 2008) have shown that fatal falls rates increase exponentially with age for

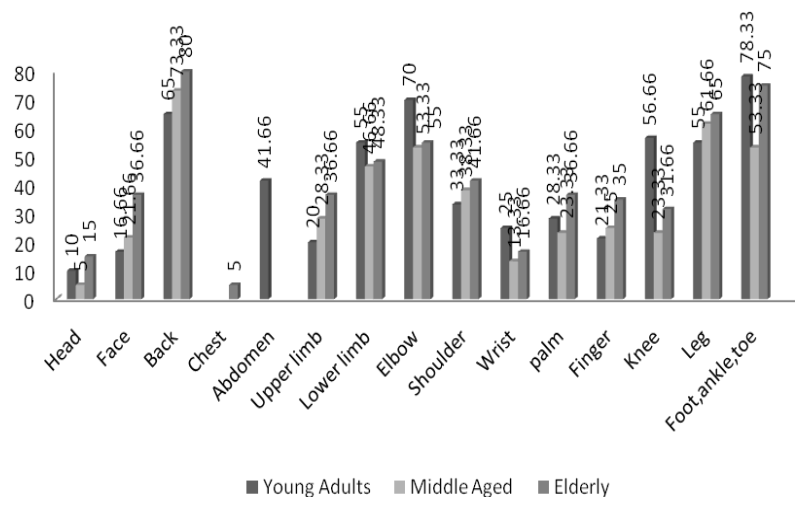

Fig. 5. Body part affected due to STF among different age group respondents (percentage). 


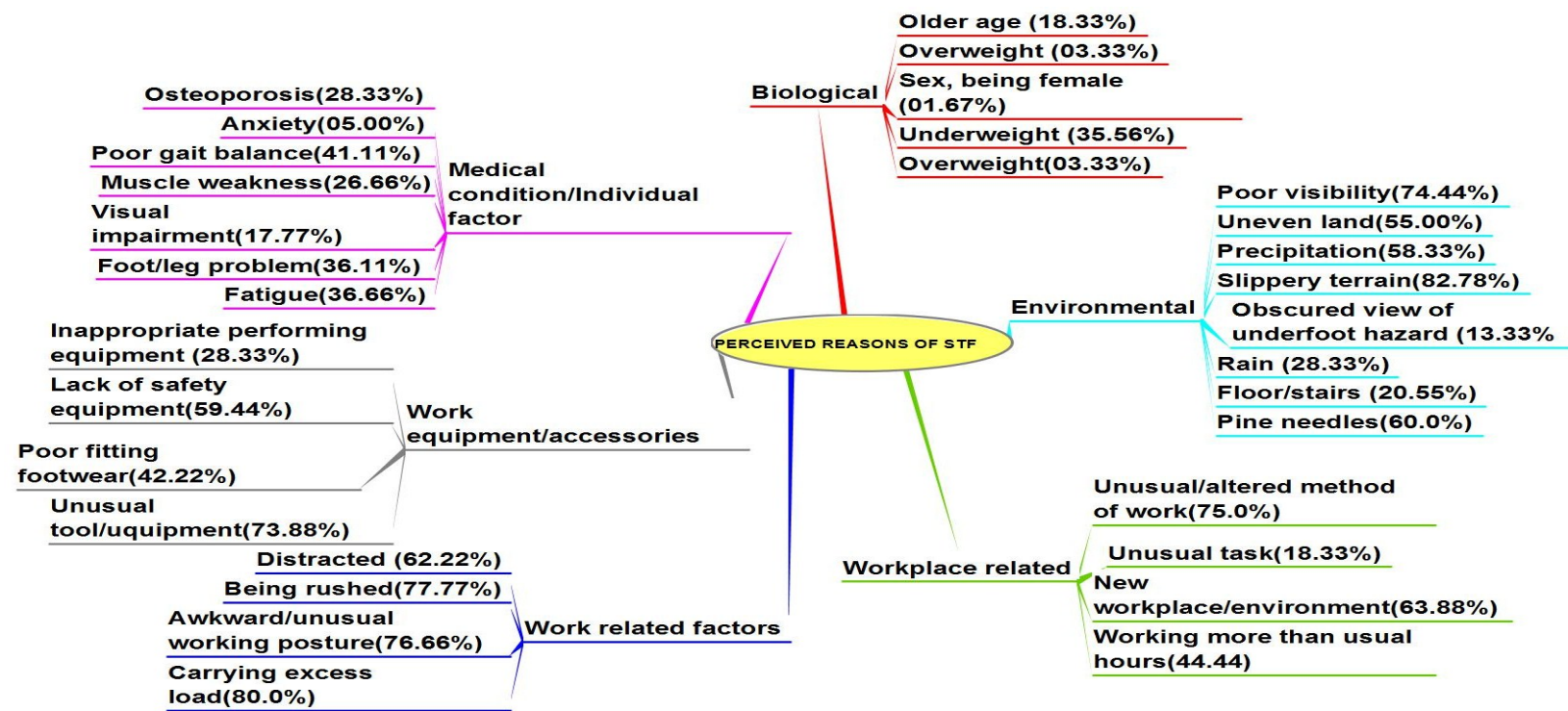

Fig 6. Possible perceived reasons of STF proposed by the respondents $(n=180)$.

both sexes, highest at the age of 85 years and over. In a similar study Kemmlert and Lundholm (2001) found that older workers suffer higher rates of injuries due to STF incidents with the effect being more pronounced in women. Stevens et al. (2014) in a study of older adults at high risk for falls found that most falls occurred at home and that women and people aged 85 and older were most likely to be injured.

Immediate effect of the STF faced by the respondents and the affected body part: Previous investigations (Campbell et al., 1981; Tinetti et al., 1988; Ryynanen, 1991; Lord et al., 1992) have reported that round $40-60 \%$ of falls lead to injuries, with $30-50 \%$ being minor injuries, 5-6 \% major injuries excluding fractures and $5 \%$ being fractures. Jagnoor et al. (2012) in their study found that falls were the second leading cause of hospital emergency presentations and half of all the falls resulted in head injury. Nearly $10 \%$ of patients presenting for fall related injury died. The immediate effects of STF reported by the hill women is presented in Fig. 4. It was found that majority of respondents i.e. $76.67 \%$ of the total respondents reported that because of the slip, trip falls accident they either hurt their back and/or they suffered from back pain, followed by $72.22 \%$ of the respondents reporting general pain or injury because of STF. $45.00 \%$ of respondents also reported fractures and $42.22 \%$ reported dislocation as the effect of the STF accident they faced. Other effects reported include abrasions, spinal injury, facial injury, sprains, multiple surface wounds, mobility and balance problems.

Further we can see that among young adults majority i.e. $71.67 \%$ suffered from general pain/injury as the effect of STF, followed by mobility and balance problems reported by $66.67 \%$ young adults. Among middle aged adults maximum $81.66 \%$ reported that they suffered from back pain/hurt pain injury followed by
$63.33 \%$ suffered from general pain/ injury. In case of elderly adults highest $76.67 \%$ respondents said that they suffered from general pain/injury followed by $53.33 \%$ respondent suffered from fracture incidents.

Fig. 5 shows the details of body part affected due to STF accident faced by the respondents. It was found that majority of respondents i.e. $72.78 \%$ the total respondents reported that because of the STF accident mainly face was affected followed by $68.89 \%$ of the respondent answered that foot, ankle or toe were affected. Leg was reported by $60.56 \%$, elbow by 59.44 $\%$ followed by $50 \%$ respondents reporting lower limb affected due to STF accident they faced.

Further we can see that among young adults majority i.e. $78.33 \%$ reported that foot, ankle or toe affected due to STF, followed by minimum $56.66 \%$ respondent reported that knees were mostly affected body part. Among middle aged adults maximum $73.33 \%$ reported that back body was affected followed by $61.66 \%$ reporting leg was affected because of STF accident. On the other hand, in case of elderly $80 \%$ respondents reported that because of slips, trips and falls accident mostly back body was affected and minimum (05.00 $\%$ ) respondents said that chest was affected.

Identification of Possible Perceived Reason for STF: Certain activities or decisions may increase the risk of falls and fall-related injuries. Examples are walking without footwear, rushing for work, environment with inadequate lighting, and tiredness etc. Information from respondents was collected in this regard, on the views of respondents as what reasons they consider as the reason responsible for the STF accident they faced. Data enfolded in Table 3 and Fig 6 indicate that major number of respondents $(82.78 \%)$ indicated slippery terrain as the reason for slip, trip fall accidents while at work, followed by $80.00 \%$ of respondents who reported carrying excess load as the 
major reason. Being rushed at work was reported by $77.77 \%$ respondent, awkward or unusual working posture reported by $76.66 \%$ respondents. About 75.00 $\%$ of respondents also reported unusual or altered working method as the possible reason for STF accident. Other major reasons reported include poor visibility, unusual tool or equipment, pine tree leaves, distraction at work etc. A similar study was done by Bentley et al. (2005) to identify the possible reasons for STF in dairy sector. The major reasons identified in their study were not to see or identify an underfoot hazard due to concurrent visual task distractions, use of footwear that both lacked effective tread and that was unsuitable for the task and underfoot surface. In different age groups majority of young adults $(80.00$ $\%)$ reported slippery terrain as well as carrying excess load as the possible reason for STF accident, among middle aged majority (81.66 \%) reported carrying excess load as the possible reason, whereas among elderly majority $(90.00 \%)$ reported poor visibility as the possible reason for STF accident.

\section{Conclusion}

The present investigation found that STF are serious public health concern in the hill areas. Injuries resulting from STF include traumatic injuries due to contact with the ground or other objects and overexertion injuries (sprains and strains) resulting from recovery efforts. These injuries cause serious reductions in quality of life, lead to huge costs, and even result in death. As human, accident cannot be avoided but human can reduce it or take a first step to prevent it from occurring especially at workplace because workplace is an area that most people would spend their daytime there. There is a need to turn the attention of policy makers and researchers towards such neglected aspects of these interior rural hill areas. Preventive steps taken in this direction could aid to reduce the fatal cases of injuries and accidents due to STF and thereby increase the health status, productivity, income and living condition of hill people.

\section{ACKNOWLEDGEMENTS}

The University Grant Commission, New Delhi, India is acknowledged for providing the financial support in the form of UGC Doctoral Research Fellowship to Ms Hema Bhatt.

\section{REFERENCES}

Abeysekera, J. (2001). The identification of factors in the systematic evaluation of slip prevention on icy surfaces. Industrial Ergonomics, 28(5):313

Bentley, T., Tappin, D., Moore, D., Legg, S., Ashby, L. and Parker, R. (2005). Investigating slips, trips and falls in the New Zealand dairy farming sector. Ergonomics, 48 (8): 1008-1019.

Berg, W. P., Alessio, H. M., Mills, E. M. and Tong, C.
(1997). Circumstances and consequences of falls in independent community-dwelling older adults. Age and ageing, 26(4): 261-268

Buck, P. C. and V. P. Coleman. (1985). Slipping, Tripping and Falling Accidents at Work: A National Picture. Ergonomics, 28 (7): 949-958

Burea of Labor Statistics (2012). United States Department of Labor, National Census of Fatal Occupational Injuries in 2012.

Campbell A.J., Reinken J., Allan B.C. and Martinez G.S. (1981). Falls in old age: a study of frequency and related clinical factors. Age ageing, 10: 264-70

Cause of death in India (2001-2003). Sample registration system. New Delhi: Registrar General of India and Centre for Global Health Research; 2009. Centers for disease control and prevention. Web-based injury statistics query and reporting system (WISQARS). Available at: http://www.cdc.gov/injury/ wisqars

Dandona R., Kumar G. A., Ivers R., Joshi R., Neal B. and Dandona L. (2010). Characteristics of non-fatal fall injuries in rural India. Inj Prev., 16:166- 171

Davis, Ross, P. D., Nevitt, C. and Richart D. (1999). Risk factors for falls and for serious injuries on falling among older Japanese women in Hawaii. Journal by American Geriatrics Society, 47:792-798

Donoghue, J., Graham, J., Gibbs, J. and Mitten-Lewis, S. (2003). Who, where and why:situational and environmental factors contributing to patient falls in the hospital setting. Aust Health Rev., 26(3):79-87

European Agency for Safety and Health at Work (EUOSHA). (2001). Preventing Accidents at Work. Luxembourg: Office for Official Publications of the European Communities. ISSN, 1608-4144

European Commission (2008). Causes and Circumstances of Accidents at Work in the EU. Luxembourg: Office for Official Publications of the European Communities.

Gao, C. and Abeysekera, J. (2004). A systems perspective of slip and fall accidents on icy and snowy surfaces. Ergonomics, 47: 573-98

Gronqvist, R. and Hirvonen, M. (1995). Slipperiness of footwear and mechanisms of walking friction on icy surfaces. International Journal of Industrial Ergonomics, Sep; 16(3):191-200

Gururaj G., Sateesh V. and Rayan A. (2008). Bengaluru injury/road traffic injury surveillance programme: a feasibility study. Bengaluru: National Institute of Mental Health and Neuro Science.

Hitcho E. B., Krauss M. J., Birge S., Dunagan W. C., Fischer I., Johnson S., Nast P. A., Costantinou E. and Fraser V. J.(2004). Characteristics and Circumstances of Falls in a Hospital Setting. J. Gen.Intern. Med., 19:732-739

Jagnoor, J., Suraweera, W., Keay, L., Ivers, R. Q., Thakur, J. S., Gururaj, G. and Jha, P. (2011). Childhood and adult mortality from unintentional falls in India. Bulletin of the World Health Organization, 89(10): 733-740

Jagnoor, J., Keay, L., Ganguli, A., Dandona, R., Thakur, J. S., Boufous, S., Cumming, R. and Ivers, R. Q. (2012). Fall related injuries: A retrospective medical review study in North India. Injury, 43(12):1996-2000

Johnson S. J. (2006). Frequency and nature of falls among older women in India. Asia Pac J Public Health, 18:5661

Kemmlert, K. and Lundholm L. (1998). Slips, trips and falls in different work groups with reference to age. Safety 
Science, 28 (1): 59-75.

Kemmlert, K. and Lundholm, L. (2001). Slips, trips and falls in different work groups- with reference to age and from a preventive perspective. Applied Ergonomics, 32: 149-153

Krishnaswamy B., Usha G. (2010).Falls in older people: national /regional review India.New Delhi : Madras Medical College and Government General Hospital, Chennai City, Tamil Nadu State, India.

Kumar, R. and Singh, P. (2013). Orthopedic trauma in hilly area of Kumaon region: A clinico epidemiological study. Indian Journal of Research and Reports in Medical Sciences, 3(2):13-15.

Leamon, T. B. and Murphy, P. L. (1995). Occupational slips and falls: more than a trivial problem. Ergonomics, 38 (3) : 487-498

Leroux, A., Fung, J. and Barbeau, H. (2002). Postural adaptation to walking on inclined surfaces: I. Normal strategies. Gait Posture, 15 (1): 64-74

Lincoln, A. E., Sorock, G. S. and Courtney, T. K. (2004). Using narrative text and coded data to develop hazard scenarios for occupational injury interventions. Injury Prevention, 10: 249-254

Lord, S. R., McLean, D. and Stathers, G. (1992). Physiological factors associated with injurious falls in older people living in the community. Gerontology, 38(6):338-346

Manning, D. P. and Shannon, H. S. (1981). Slipping accidents causing low-back pain in a gearbox factory, spine. 6:70-72

Mittal, S. (2008). Development strategy for the hill districts of Uttarakhand, Indian Council For Research On International Economic Relations.

Nachreiner, N.M., Findorff, M.J., Wyman, J.F. and McCarthy, T.C. (2007). Circumstances and consequences of falls in community-dwelling older women. Journal of Women's Health, 16(10): 1437-1446

Nakai, A., Akeda, M. and Kawabata, I. (2006). Incidence and risk factors for inpatient falls in an academic acute-care hospital. J Nippon Med Sch., 73: 265-270

Navaratne K., Fonseka P., Rajapakshe L., Somatunga L., Amertunga S. and Ivers R. ( 2009). Population-based estimates of injuries in Sri Lanka. Inj Prev., 15:170-175

Nenonen, N. (2013). Analysing factors related to slipping, stumbling, and falling accidents at work: Application of data mining methods to finish occupational accidents and diseases statistics database. Applied Ergonomics, 44 (2): $215-224$

Redfern, M. S. and DiPasquale J. (1997). Biomechanics of descending ramps. Gait and Posture, 6:119-25

Rubenstein, L. Z. (2006). Falls in older people: epidemiology, risk factors and strategies for prevention. Age and ageing, 35(suppl 2):37-41

Ryynanen, O. P., Kivela, S. L. and Honkanen, R. (1991). Incidence of falling injuries leading to medical treatment in the elderly. Public Health, 105: 373-86.

Sattin, R.W., Huber, D.A.L., Devito, C.A., Rodriguez, J.G., Ros, A., Bacchelli, S. and Waxweiler, R. J. (1990). The incidence of fall injury events among the elderly in a defined population. American Journal of Epidemiology, 131(6): 1028-1037

Stevens, J.A., Mahoney, J.E. and Ehrenreich, H. (2014). Circumstances and outcomes of falls among high risk community-dwelling older adults. Injury epidemiology, 1(1): 5

Strandberg, L. and Lanshammar H. (1981). The dynamics of slipping accidents. Journal of Occupational Accidents, 3 (3): 153-162

Tinetti, M.E., Speechley, M. and Ginter, S.F. (1988). Risk factors for falls among elderly persons living in the community. N Engl J Med., 319: 1701-1707.

Tromp A.M., Pluijm S.M.F., Smit J.H., Deeg, D.J.H., Bouter L.M. and Lips, P. (2001). Fall-risk screening test: a prospective study on predictors for falls in communitydwelling elderly. J Clin Epidemiol., 54(8):837-44

World Health Organization. Ageing, andLife Course Unit. (2008). WHO global report on falls prevention in older age. World Health Organization.

Yeoh, H.T., Lockart, T.E. and X. Wu. (2013). Non-fatal Occupational Falls on the Same Level. Ergonomics, 56 (2): $153-165$ 